Boletín de la Sociedad Geológica Mexicana

VOLUMEN 64, NÚM. 3, 2012, P. 411-425

\title{
Geología de la región de Salamanca, Guanajuato, México
}

\author{
Ángel Francisco Nieto-Samaniego ${ }^{1, *}$, Ángel Catarino Ojeda-García ${ }^{1}$, \\ Susana A. Alaniz-Álvarez ${ }^{1}$, Shunshan $\mathrm{Xu}^{1}$ \\ ${ }^{1}$ Universidad Nacional Autónoma de México, Campus Juriquilla, Centro de Geociencias, Boulevard Juriquilla 3001, Juriquilla, Qro., \\ Querétaro, CP 76230, México. \\ *afns@geociencias.unam.mx
}

\section{Resumen}

Se realizó la cartografía geológica de la región Salamanca-Aldama, en el Estado de Guanajuato, en escala 1:50,000. El área se ubica entre las provincias fisiográficas Faja Volcánica Transmexicana (FVTM) y Mesa Central (MC). En el trabajo de campo se lograron distinguir dieciséis unidades cartografiables. La unidad más antigua a nivel regional está formada de rocas sedimentarias marinas correspondientes al complejo volcanosedimentario de la Sierra de Guanajuato, de edad Jurásico Tardío-Cretácico Temprano (Titoniano-Hauteriviano), dicha unidad no aflora dentro del área cartografiada. La unidad más antigua aflorante es un conglomerado continental, polimíctico, que correlacionamos con el conglomerado Rojo de Guanajuato. Sobre esa unidad aparece una andesita y encima de ella, hay domos y lavas riolíticos que correlacionamos con las "riolitas topacíferas" del volcanismo oligocénico de la Mesa Central, aunque no se ha detectado la presencia de topacios en estas rocas dentro del área cartografiada. Se identificaron también tres unidades ignimbríticas de edad Oligoceno tardío-Mioceno temprano, las cuales consideramos que son parte de la cubierta ignimbrítica de la Mesa Central y contienen intercalada una unidad de andesita. Cubriendo a las ignimbritas logramos identificar dos unidades de andesita-basalto, una constituye los depósitos asociados a la caldera La Ordeña, y la otra forma mesetas de lava distribuidas en buena parte del área de estudio. Adicionalmente se identificaron aparatos volcánicos monogenéticos y derrames de lava que fueron agrupados como volcanismo perteneciente a la Faja Volcánica Transmexicana.

Las fallas más antiguas que se cartografiaron tienen dirección NO-SE y se localizan en la parte noreste del área de estudio, esas fallas solo cortan a los derrames y domos riolíticos de edad oligocénica. Otro conjunto de fallas tiene direcciones que van de NE a ENE y corta a las unidades ignimbríticas. La estructura más importante del área es la falla El Bajío, tiene un rumbo preferencial NO-SE, presenta un desplazamiento de $c a .500 \mathrm{~m}$, se documenta que los últimos movimientos afectaron a rocas del Mioceno tardío, y formó la fosa tectónica denominada El Bajío. Dicha fosa es el límite entre la Faja Volcánica Transmexicana y la Mesa Central. En la parte sur del área de estudio se observaron algunas fallas normales de rumbo N-S que cortan a las rocas de la Faja Volcánica Transmexicana, de edad Plioceno-Cuaternario.

Palabras clave: Falla de El Bajío, mapa geológico de Salamanca, estratigrafía volcánica, volcanismo cenozoico.

\begin{abstract}
Geological cartography of the Salamanca-Aldama region in the state of Guanajuato, Mexico, was carried out at a scale of 1:50000. The study area is located between the Transmexican Volcanic Belt and the Mesa Central physiographic provinces. During field work we identified 16 stratigraphic units. The oldest unit at a regional level is formed of sedimentary marine rocks, which belong to the Late Jurassic - Early Cretaceous (Tithonian-Hauterivian) Sierra de Guanajuato volcanosedimentary complex. This unit does not crop out within the study area. The oldest outcropping unit in the mapped area is a continental polymictic conglomerate, which is correlated with the "Guanajuato Red Conglomerate". An andesitic unit covers the conglomerate, and rhyolite domes and lava flows overlie the andesite. Although no topaz was observed during fieldwork, we correlate those rhyolites with the "topaz bearing-rhyolites" of the
\end{abstract}


Oligocene volcanism of the Mesa Central. In addition, we identified three ignimbritic units of late Oligocene-early Miocene age. These units correspond to the ignimbritic cover of the Mesa Centra, and include an interlayered andesite unit. Two units of andesitic-basaltic composition cover the ignimbrites. One of them is formed of rocks associated with La Ordeña caldera and the other unit constitutes lava plateaus observed throughout the study area. Also, monogenetic volcanoes and some lava flows were mapped as volcanic rocks of the Transmexican Volcanic Belt.

The oldest faults mapped trend NW-SE and are located in the northeastern part of the study area. These faults cut the Oligocene rhyolitic lava flows and domes. The second group of faults have a NE to ENE trend and cut the ignimbritic cover. The most important structure is the El Bajio fault, trending NW with $500 \mathrm{~m}$ of offset. The youngest movements affected late Miocene rocks and formed the El Bajio graben, which is the boundary between the Transmexican Volcanic Belt and the Mesa Central. In the southern part of the study area N-S normal faults cut Pliocene-Quaternary rocks of the Transmexican Volcanic Belt.

Keywords: El Bajío fault, geologic map of Salamanca, volcanic stratigraphy, Cenozoic volcanism.

\section{Introducción}

La región de Salamanca, Guanajuato, se localiza en el límite entre las provincias geológicas Faja Volcánica Transmexicana (FVTM) y la Mesa Central (MC) (Figura 1). La FVTM es un arco volcánico continental de edad Mioceno-Cuaternario de composición principalmente andesítica (e.g., Ferrari et al., 2000). Por otra parte, en la zona meridional de la $\mathrm{MC}$ afloran principalmente rocas de un arco volcánico de edad Paleógeno y de composición principalmente ácida (e.g., Nieto-Samaniego et al., 2005). Se cuenta con información geológica de buena parte de ambas provincias, así como también con fechamientos isotópicos de los conjuntos volcánicos mayores (GómezTuena et al., 2005; Nieto-Samaniego et al., 2005). Sin embargo, particularmente en la región de Salamanca, solo se cuenta con cartografía geológica en escalas 1:250000 o mayores, aunque en regiones adyacentes sí hay mapas geológicos en escala 1:50000, debido a la presencia de importantes depósitos minerales que han propiciado la cartografía geológica a mayor detalle.

En el área de estudio se sobreponen las rocas del volcanismo oligocénico, presente en la Mesa Central (MC), y el volcanismo Mioceno-Cuaternario de la FVTM (Figuras 1 y 2). También en esa región se localiza parte de la traza de la Falla El Bajío, la cual limita a las provincias mencionadas y constituye una de las fallas mayores del centro de México (Nieto-Samaniego et al., 2005).

A partir de los mapas publicados sobre la región de estudio (Alvarado-Méndez et al., 1998; Pérez-Flores et al., 1999; Nieto-Samaniego et al., 1999a, 1999b; CercaMartínez et al., 2000; López-Ojeda et al., 2002), así como de estudios regionales sobre la estratigrafía y evolución tectónica de la región centro-septentrional de México (Labarthe-Hernández et al., 1982; Aranda-Gómez et al., 1989; Nieto-Samaniego et al., 1996, 1999c, 2005; TristánGonzález et al., 2009) se conoce que hay dos grandes conjuntos litológicos, uno formado por rocas mesozoicas marinas, deformadas por acortamiento, y el otro que consiste de un conjunto de rocas cenozoicas continentales,

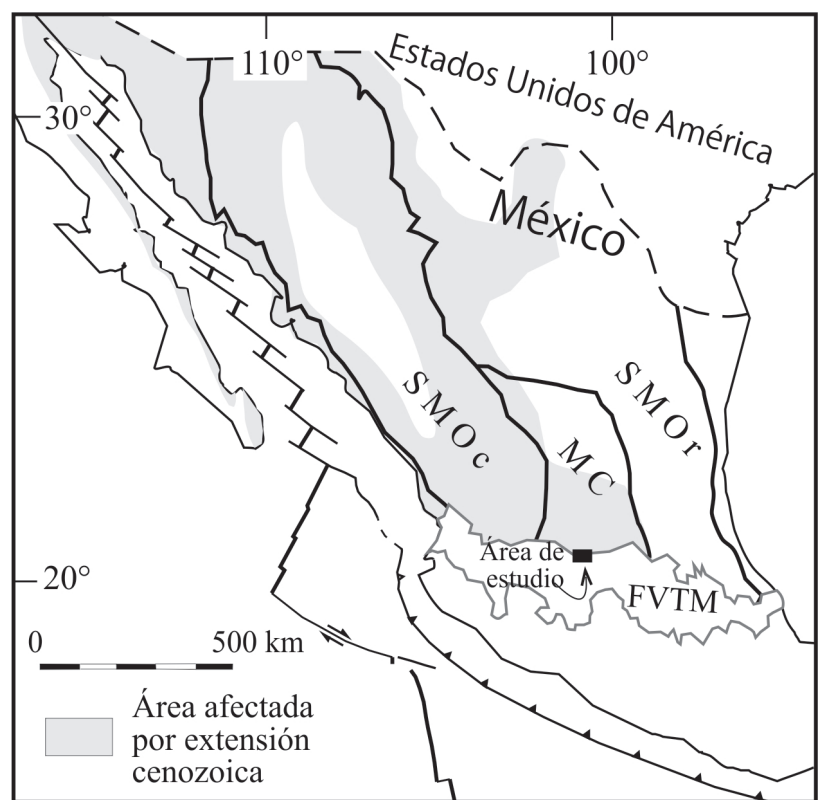

Figura 1. Localización del área de estudio. Se indican las provincias fisiográficas siguientes: SMOc Sierra Madre Occidental, MC Mesa Central, SMOr Sierra Madre Oriental, FVTM Faja Volcánica Transmexicana.

sedimentarias y volcánicas, que han sido afectadas por fallas principalmente normales. En el área cubierta en el presente estudio afloran casi exclusivamente las rocas cenozoicas (Figura 2).

En este estudio se llevó a cabo la cartografía geológica de la carta Salamanca (F-14-C-63) y una parte de la carta Aldama (F-14-C-53), editadas por Instituto Nacional de Estadística, Geografía e Informática (INEGI) en escala 1:50000, ambas del Estado de Guanajuato. Con la cartografía reportada aquí se completa la información geológica a lo largo del límite Sur de la Mesa Central, ya que la región de Salamanca era la única área que restaba por cartografiar en escala 1:50000 a lo largo de la traza del sistema de fallas El Bajío, la cual se extiende desde Celaya hasta León, en el estado de Guanajuato.

Presentamos en esta contribución una división litoestratigráfica de las rocas cenozoicas cartografiadas, tanto 


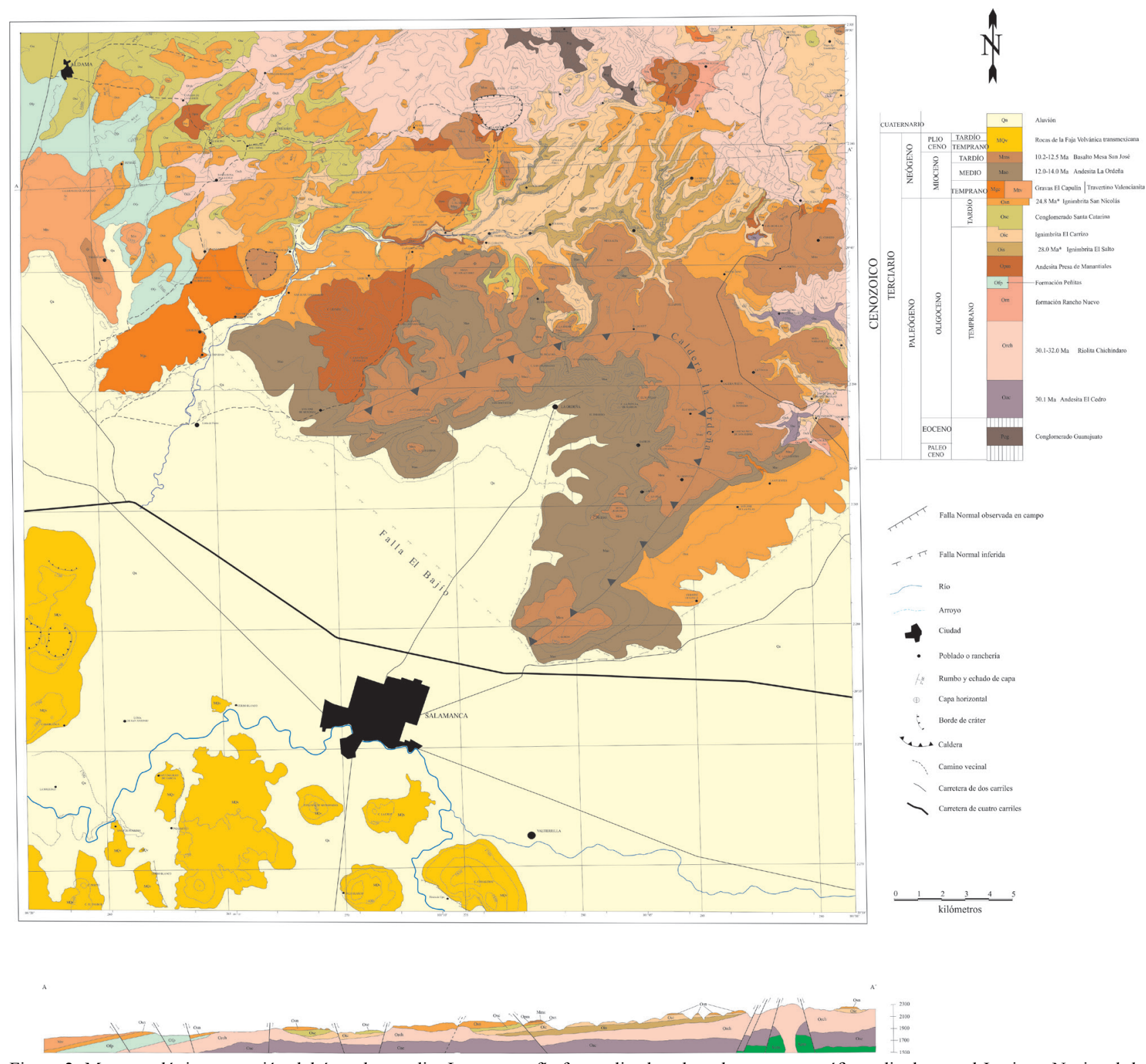

Figura 2. Mapa geológico y sección del área de estudio. La cartografía fue realizada sobre el mapa topográfico editado por el Instituto Nacional de Estadística Geografía e Informática de México (INEGI), que utiliza el datum NAD23 para las coordenadas UTM. Las curvas de nivel fueron elaboradas a partir del "Continuo de elevación Mexicano CEM (2.0)" que pone en acceso libre el INEGI en la dirección (http://www.inegi.org.mx/geo/contenidos/ datosrelieve/continental/Descarga.aspx).

volcánicas como sedimentarias. Compilamos también las edades isotópicas disponibles en la literatura y presentamos el ordenamiento estratigráfico de las unidades que afloran en el área de estudio. Con base en la organización de unidades litoestratigráficas que proponemos, reconstruimos la evolución geológica del área, proponemos los eventos magmáticos y tectónicos más importantes que logramos reconocer y discutimos su correlación con aquellos eventos que ya han sido establecidos regionalmente.

\section{Estratigrafía}

\section{Rocas Mesozoicas (Krm)}

Las rocas mesozoicas no afloran dentro del área de estudio, pero han sido cartografiadas hacia el norte y oriente del área cubierta por la Figura 2. Los afloramientos más cercanos aparecen en el Distrito Minero de Guanajuato ubicado $20 \mathrm{~km}$ al Norte y en la región de Celaya ubicada $15 \mathrm{~km}$ al Oriente; en este trabajo suponemos su presencia en el subsuelo, como aparece interpretado en las secciones de la Figura 2. Son rocas marinas volcanosedimentarias 
deformadas por acortamiento, que presentan en muchas localidades metamorfismo de grado bajo en las facies de esquistos verdes (e.g., Martínez-Reyes, 1992).

\subsection{Conglomerado Guanajuato (Pcg)}

Son las rocas más antiguas que afloran en el área de estudio, los afloramientos solo aparecen en las localidades de Joya de Cortés y Potrerillos (Figura 2). En los afloramientos del área cartografiada se reconocieron las siguientes litologías: caliza micrítica de color azul, cuyo espesor es de 20 a $30 \mathrm{~cm}$ y una arenisca arcósica de color verde, las sobreyace una arenisca conglomerática de grano grueso, con estratificación fina, de color café. Los clastos que componen la parte conglomerática son de lutita y arenisca, además hay intercalada una limolita de color amarillo. La parte superior de la formación está constituida por una arenisca de grano fino de color verde.

Hay brechas calcáreas que contienen cantos que llegan a medir hasta $20 \mathrm{~cm}$ y son principalmente de arenisca arcósica, marga y caliza micrítica color azul a negra. Los cantos de margas son los menos comunes. La estratificación es de fina a delgada, los clastos son angulosos y mal clasificados y se presentan en contacto unos con otros. La brecha contiene intercalaciones de arenisca; se observaron varias repeticiones de $c a .1 \mathrm{~m}$ de brecha con 30-40 cm de arenisca de color café y muy físil, de grano fino cuyo componente principal es cuarzo, los granos de cuarzo se observaron cementados por carbonato de calcio. En los lugares donde las rocas mesozoicas están en contacto con domos riolíticos se las observa muy alteradas, sobre todo las areniscas de la cima, que están un poco cloritizadas y oxidadas, lo cual se observó mejor en la Joya de Cortés (Figura 2).

\subsection{Andesita El Cedro (Oac)}

Denominamos Andesita El Cedro a un grupo de rocas de composición andesítica que afloran en la base de la cubierta cenozoica. Esta unidad ha sido identificada en toda la región, Bostford (1909) se refirió a ella como "brechas y tobas andesíticas" y Wandke y Martínez (1928) como "tobas, brechas y derrames andesíticos". Echegoyén-Sánchez et al. (1970) la denomina Formación Cedro, proponiendo como su localidad tipo el poblado El Cedro, ubicado en las cercanías de la ciudad de Guanajuato, Gto. Esta unidad fue cartografiada en el área de estudio y en lugares aledaños por Cerca-Martínez et al. (2000), quien la describió como flujos de lava basáltica de color oscuro, intemperizado y al parecer oxidado, con fenocristales de olivino y piroxeno y que en lámina delgada presenta una textura porfídica con cristales de plagioclasa zonada y piroxeno, en una matriz microcristalina.

La Andesita El Cedro solo aflora en tres localidades del área de estudio, todas ubicadas en la parte oriental del mapa: se la encuentra al norte del rancho Las Ardillas, en San Isidro de los Dolores y al oeste de Chupaderos (Figura
2). Se compone de derrames de lava que en muestra de mano se aprecia con escasos fenocristales de plagioclasas inmersas en una matriz afanítica. La roca se distingue por tener colores rojizos a verdosos cuando la roca está alterada o intemperizada. En el afloramiento de Las Ardillas presenta colores morado y azul claros, o bien, verde con bandas rojas de óxido. En ese lugar la roca está muy intemperizada, es deleznable, formando lomeríos pequeños. Presenta facies piroclásticas de color rojo a marrón y estratificación delgada, formada preponderantemente de clastos de composición andesítica, aparecen en menor proporción algunos líticos de color más claro $(10 \%)$. Los clastos son de angulares a sub-angulares y están contenidos en una matriz clástica del tamaño de arena.

La Andesita El Cedro yace discordantemente bajo la Riolita Chichíndaro, o en ausencia de dicha unidad, bajo la ignimbrita El Carrizo. Es común observar diques de composición riolítica en la Andesita El Cedro que interpretamos como pertenecientes a las unidades que la cubren. Esta relación se puede observar muy bien entre los poblados de San Isidro de los Dolores y El Naranjillo, donde los domos de la Riolita Chichíndaro son fácilmente apreciables emplazados en la Andesita El Cedro.

En el presente trabajo no fue posible medir el espesor de esta unidad, ya que no aflora su base. Fuera del área de estudio otros autores le han asignado espesores de entre 250 y 650 m (Echegoyén-Sánchez et al., 1970; Gross, 1975).

Cerca-Martínez (1998) realizó dos fechamientos isotópicos de esta unidad por el método K-Ar, uno en roca entera y otro en matriz. Las muestras fueron colectadas en lugares ubicados a menos de $10 \mathrm{~km}$ al norte y noreste del área de estudio. Las edades que obtuvo fueron $30.6 \pm 0.4 \mathrm{Ma}$ y $30.7 \pm 0.4$ Ma lo que la ubica en el Oligoceno temprano.

\subsection{Riolita Chichíndaro (Orch)}

En este trabajo adoptamos el nombre de Riolita Chichíndaro para referirnos a un conjunto de rocas volcánicas de composición ácida, principalmente derrames de lava y domos riolíticos, que afloran en la parte norte y este del área de estudio (Figura 2).

Las primeras referencias a esta unidad datan de inicios del siglo pasado, cuando fue descrita por Bostford (1909) en los alrededores de Guanajuato, Gto. Posteriormente fue descrita en esa misma zona por Echegoyén-Sánchez et al. (1970) quién usó el nombre riolita Chichíndaro.

En el área de estudio esta unidad esta constituida por derrames de lava y depósitos piroclásticos, todos de composición ácida, que generalmente forman domos riolíticos. A las estructuras dómicas se asocian diques, brechas tanto en las lavas como en depósitos piroclásticos y vitrófidos que aparecen comúnmente entre los depósitos piroclásticos y las lavas. Las riolitas presentan colores blanco, rosado, rojizo y morado. La mineralogía que se observa en muestra de mano es cuarzo + feldespato potásico (sanidino) $>$ biotita, en una matriz afanítica. En la matriz 
se observan planos de flujo muy bien definidos, en algunos lugares se encuentran contorsionados, formando pliegues de flujo. Los depósitos de caída comúnmente son de color blanco y se identificaron por presentar soporte clasto a clasto. Por otra parte, los flujos piroclásticos presentan clastos soportados por matriz, o bien, estructuras de flujo, así como coloraciones rosadas o verdosas. Tanto los depósitos de caída como los flujos piroclásticos se encuentran asociados a las estructuras de domo. En algunos casos los domos se presentan alterados por oxidación, argilización y cloritización. Un ejemplo de la alteración por óxidos se puede observar en la carretera libre Celaya-Guanajuato, cerca del poblado de Agua Zarca (Figura 2).

Al microscopio se observa una textura eutaxítica, formada por las estructuras de flujo de la lava. Es una roca porfídica, con fenocristales que tienen tamaños de 0.1 a $1 \mathrm{~mm}$, de cuarzo y sanidino, soportados por una matriz microcristalina con zonas vítreas. La mayoría de los fenocristales son de cuarzo subhedral. También se observaron líticos y zonas con agregados de cuarzo, que interpretamos como minerales secundarios.

En el área de estudio es común observar a la Riolita Chichíndaro yaciendo sobre la Andesita El Cedro, o bien sobre las rocas mesozoicas, mediante una discordancia erosional. En su contacto superior la Riolita Chichíndaro yace bajo la formación Rancho Nuevo, la ignimbrita El Carrizo, o la Ignimbrita San Nicolás (Figura 2). Su espesor es muy variable, en el área de estudio típicamente es de entre 100 y $150 \mathrm{~m}$, pero han sido reportados en la literatura espesores de hasta $400 \mathrm{~m}$ (Nieto-Samaniego et al., 1992). Lavas de la Riolita Chichíndaro han sido fechadas en varios lugares de la Mesa Central, las edades reportadas para los afloramientos localizados en Guanajauto, Gto., al norte del área de estudio, son $32 \pm 1 \mathrm{Ma}$ (K-Ar, en roca entera) (Gross, 1975); $30.8 \pm 0.8$ Ma y $30.1 \pm 0.8 \mathrm{Ma}$ (K-Ar en sanidino) (Nieto-Samaniego et al., 1996), lo que la ubica en el Oligoceno temprano.

\subsection{Formación Rancho Nuevo (Om)}

Esta unidad no había sido descrita anteriormente, la proponemos para incluir en ella los depósitos volcaniclásticos que separan a la Riolita Chichíndaro y la Andesita Presa de Manantiales, y que afloran principalmente en los alrededores del poblado de Rancho Nuevo (Figura 2). El nombre se toma del arroyo Rancho Nuevo, donde se ubica un afloramiento extenso. La formación Rancho Nuevo consiste de una secuencia de depósitos volcaniclásticos con granulometría de areniscas de grano fino, estratificación cruzada y coloración café claro a blanquecino, con algunos horizontes oscuros; contiene pómez cuyos tamaños van desde 0.2 hasta $2 \mathrm{~cm}$, así como algunos clastos de riolita. La estratificación varía de delgada a gruesa. En el poblado de Rancho Nuevo se presenta de forma masiva y tiene intercalado un conglomerado de estratificación gradada normal, con matriz arenosa y con clastos que van desde $0.5 \mathrm{a} 20 \mathrm{~cm}$, casi en su totalidad son de riolita; dicho conglomerado presenta colores que van de blanco a rojizo. En la localidad de El Rinconcillo se presenta como una toba arenosa, con una gran cantidad de pómez de tamaño de 0.5 a $2 \mathrm{~cm}$; también contiene líticos de composición riolítica y cuarzo, presenta estratificación de delgada a gruesa y tiene color blanco.

El espesor de la formación Rancho Nuevo se estima en $400 \mathrm{~m}$, medidos en el arroyo Rancho Nuevo. Se la observa yaciendo sobre la Riolita Chichíndaro y bajo la Andesita Presa de Manantiales, en ambos casos los contactos son discordantes. En el área de El Rinconcillo se encuentra directamente debajo de la Ignimbrita San Nicolás (Figura 2). Por su posición estratigráfica se ubica en el Oligoceno temprano.

\subsection{Formación Peñitas (Ofp)}

El nombre se toma del poblado de Peñitas, donde esta unidad aflora extensamente. La formación Peñitas está constituida de dos litologías, una toba arenosa y una arenisca. La primera litología, que se ubica hacia la parte baja de la unidad, es un depósito piroclástico con granulometría de arena, la cual solo aflora en Aldama y en Peñitas. Consiste de fragmentos de pómez con diámetros que van desde $1 \mathrm{~mm}$ hasta $5 \mathrm{~cm}$, el resto de los componentes son en su mayoría cuarzo y clastos de riolita cuya granulometría es de arena fina a media en una matriz de ceniza. El color de esta unidad es café claro y está poco consolidada, es muy deleznable. Consideramos que esta litología es muy parecida a la formación Rancho Nuevo y posiblemente se correlacione con ella, ya que tienen la misma posición estratigráfica.

La arenisca aflora $c a .2 \mathrm{~km}$ al SO del poblado Cañada de la Muerte, en el pueblo de Peñitas y en Ojo de Agua de Bermúdez, en cada uno de esos lugares la arenisca presenta características particulares. En la Cañada de la Muerte, ubicada a cinco kilómetros al oeste de Aldama (Figura 2), se presenta como una arenisca de grano grueso a conglomerática, cementada por sílice. Los cantos de la arenisca conglomerática son de riolita en un $75 \%$, de cuarzo en un $15 \%$ y de andesita en un $10 \%$. Tiene intercalados horizontes delgados de conglomerado, cuyos cantos son de riolita y basalto, contenidos en una matriz arenosa similar a la arenisca descrita. Los cantos en esos conglomerados están bien redondeados y pueden llegar a medir hasta 20 $\mathrm{cm}$. En el afloramiento de Peñitas (Figura 2), la arenisca es de grano medio, cementada por calcita y contiene nódulos de carbonato de calcio que miden aproximadamente cinco centímetros. Los cantos son de riolita, en su mayoría, y en proporción menor de cuarzo. El color de esta unidad es de amarillo blanquecino a café claro. La estratificación es de media a delgada y aunque no se observó ningún estrato de travertino, se encontraron cantos rodados de ese material en los alrededores de ese afloramiento. Un tercer afloramiento se localiza al poniente de Ojo de Agua de Bermúdez (Figura 2). En ese lugar la arenisca está poco consolidada y es de grano medio, los cantos son de cuarzo en un $70 \%$, riolita 
en un $20 \%$ y de ignimbrita en un $10 \%$. El cementante es calcita principalmente, hay también nódulos de calcita aunque no son abundantes. El color de la arenisca es marrón claro a blanco. La estratificación de esta unidad es gruesa, tiene intercalaciones de travertino color blanco, en capas de $c a .50 \mathrm{~cm}$ de espesor. El travertino es de color blanco a gris y presenta formas contorsionadas dentro de sus estratos.

El espesor total no fue posible medirlo, pues nunca se pudo observar la base de la unidad, solamente se puede estimar el espesor que aflora, que es cercano a $30 \mathrm{~m}$.

\subsection{Andesita Presa de Manantiales (Opm)}

Esta unidad fue descrita por Nieto-Samaniego (1992) cuatro kilómetros al noreste del área de estudio, describiéndola como rocas de composición andesítica, que cubren a la riolita Chichíndaro y que yacen bajo sedimentos continentales. Dentro del área cartografiada en el presente estudio aparece a manera de afloramientos aislados, en la parte norte de la Figura 2.

La andesita Presa de Manantiales está formada por derrames andesíticos de textura porfídica; presenta una coloración que varía de café oscuro a negro. En los alrededores de Rancho Nuevo se presenta como una andesita de color gris oscuro y matriz afanítica. Se observa con estructura masiva formando una meseta con escarpes pronunciados. En el poblado de Las Ardillas la andesita es muy deleznable y presenta un color de negro a morado y hacia el sur de esta misma localidad, aparece un derrame vesicular con olivino que forma mesetas, el cual tiene más un aspecto de basalto que de andesita.

LaAndesita Presa de Manantiales yace concordantemente sobre la formación Rancho Nuevo y bajo la ignimbrita El Salto, aunque este último contacto no fue observado directamente en afloramiento. En el área de Rancho Nuevo se la observa cubierta discordantemente por la ignimbrita El Carrizo. En el cerro El Estanco se la encuentra bajo el Conglomerado Santa Catarina. Al sur de las Ardillas aparece bajo la ignimbrita El Carrizo y cubriendo a la andesita El Cedro.

En este trabajo el espesor no fue medido, se estima que supera los $100 \mathrm{~m}$. Su edad queda restringida al Oligoceno temprano al cubrir a la riolita Chichíndaro de $c a .30 \mathrm{Ma}$ (K-Ar en sanidino) (Nieto-Samaniego et al., 1996) y yacer bajo la ignimbrita El Salto de ca. $28 \mathrm{Ma}$ (K-Ar en sanidino, Tabla 1).

\subsection{Ignimbrita El Salto (Ois)}

Denominamos ignimbrita El Salto a un conjunto de rocas volcánicas piroclásticas que aflora en el arroyo El Salto, el cual se localiza al oeste de Mesa de Almanza (Figura 2). Esta unidad consiste de flujos piroclásticos de composición ácida, que contienen pómez y líticos de composición riolítica. Forma escarpes pronunciados donde las rocas presentan una estructura columnar. La unidad es color gris claro a pardo claro, se encuentra soldada y comúnmente presentan estructuras de flama. La textura de la roca es porfídica y en muestra de mano se distinguen fenocristales de plagioclasa, sanidino y cuarzo.

En el área de Mesas de Almanza, sobre el arroyo El Salto, la roca es de color café rosado, con una gran cantidad de líticos de composición riolítica y muy pocas flamas. En muestra de mano se distinguen pequeños fenocristales de sanidino y cuarzo, inmersos en una matriz afanítica. En el camino que va hacia Mesas de Acosta la roca es un poco más oscura, muy soldada, con gran cantidad de flamas y contiene fragmentos líticos. Los fenocristales son de plagioclasa sódica, sanidino y cuarzo.

Al microscopio petrográfico se observa que es una roca leucocrática, hipocristalina. Se observa también una estructura de flujo pobremente desarrollada, en la matriz se distinguen esquirlas de vidrio. Los fenocristales son de sanidino (60-65\%), al que se aprecia crucero perfecto en 2 direcciones, cuarzo (20-25\%), ferromagnesianos (10-15 $\%$ ) y plagioclasa, cuyos ángulos de extinción indican que se trata de albita $(2-5 \%)$.

La ignimbrita El Salto tiene un espesor de $60 \mathrm{~m}$, yace bajo la ignimbrita El Carrizo con un contacto concordante. $\mathrm{Su}$ edad fue determinada por un fechamiento K-Ar en sanidino, obteniendo $28.0 \pm 1.1 \mathrm{Ma}$ (Tabla 1), por lo que se asigna al Oligoceno temprano.

\subsection{Ignimbrita El Carrizo (Oic)}

Esta unidad se describe por primera vez en el presente estudio. El nombre lo toma del arroyo El Carrizo ubicado en las cercanías de Nuevo Cimatario (Figura 2), en ella se incluye un conjunto de rocas piroclásticas que afloran extensamente en la parte central y oriental del área de estudio formando mesetas (Figura 2). La unidad está formada por flujos piroclásticos con una gran cantidad de

Tabla 1. Datos isotópicos de las muestras fechadas por el método K-Ar en Salamanca, tomada de Nieto-Samaniego et al. (2005). *Argón radiogénico.

\begin{tabular}{cccccccc}
\hline Muestra & Unidad & Mineral & $\mathbf{\% K}$ & $\begin{array}{c}\mathbf{4 0}^{\mathbf{4}} \mathbf{*} \\
\mathbf{m o l e s} / \mathbf{g}\end{array}$ & $\mathbf{\%}^{\mathbf{4 0}} \mathbf{A r} *$ & $\begin{array}{c}\text { Edad } \\
\text { (Ma) }\end{array}$ & $\begin{array}{c}\text { Coordenadas } \\
\text { UTM }\end{array}$ \\
\hline A029MDA173 & $\begin{array}{c}\text { Ignimbrita San } \\
\text { Nicolás } \\
\text { Ignimbrita el } \\
\text { Salto }\end{array}$ & Sanidino & 5.93 & $2.56 \mathrm{E}-10$ & 99 & $24.7 \pm 1.1$ & $\begin{array}{c}14 \mathrm{Q} 285018 \\
2295393\end{array}$ \\
A029MDA172 & Sanidino & 8.03 & $3.92 \mathrm{E}-10$ & 95.9 & $28.0 \pm 1.1$ & $\begin{array}{c}14 \mathrm{Q} 284842 \\
2295584\end{array}$ \\
\hline
\end{tabular}


clastos de pómez que llegan a medir hasta $15 \mathrm{~cm}$, también contiene clastos líticos de composición ácida. Las rocas que conforman esta unidad se caracterizan por estar muy poco soldadas, tener una textura muy rugosa y ser muy porosa y por contener una gran cantidad de pómez. En muestra de mano tiene un color blanco y se le reconocen cristales pequeños de sanidino y cuarzo. Al norte de Santa Rita y en la cima de la ignimbrita El Carrizo aparece una toba de grano fino, masiva, de color blanco a amarillenta. Cuando está intemperizada forma esferas en cuyo centro aparece, ya sea un clasto lítico de riolita, o de un mineral que generalmente es cuarzo. Cuando se rompen dichas esferas se aprecia que está formada por capas concéntricas. El afloramiento de esta toba es pequeño, solo se encuentra en localidad mencionada.

La ignimbrita el Carrizo forma lomeríos con escarpes muy pronunciados y profundos. En la base y en la cima tiene flujos de grano fino y color blanco, el resto de la unidad es masiva. Esta unidad yace sobre la ignimbrita El Salto por medio de un contacto concordante y está cubierta por el conglomerado Santa Catarina, por medio de un contacto transicional, intercalándose capas de rocas piroclásticas entre los sedimentos. Dicha relación puede ser observada al este de Nuevo Cimatario (Figura 2).

Al microscopio petrográfico la ignimbrita El Carrizo muestra una textura hipocristalina, eutaxítica, contiene matriz con numerosas estructuras de flama que llegan a constituir hasta un $60 \%$. Los fenocristales generalmente se presentan de anhedrales a subhedrales y son de plagioclasa sódica (40\%), cuarzo (35\%) y sanidino ( $25 \%$ ).

El espesor de la ignimbrita El Carrizo es de aproximadamente $60 \mathrm{~m}$. Por su posición estratigráfica, su edad se ubica en el Oligoceno temprano.

\subsection{Conglomerado Santa Catarina (Osc)}

Esta unidad fue descrita por Nieto-Samaniego (1992), dándole este nombre a las arenas y gravas continentales que afloran ampliamente en el poblado de El Terrero, ubicado unos cinco kilómetros al norte del área de estudio.

Comúnmente los afloramientos del Conglomerado Santa Catarina se presentan al pie de las sierras donde aflora la Riolita Chichíndaro. Dentro del área cartografiada aflora principalmente en la parte noroeste. Esta unidad es un conglomerado mal estratificado, con cantos de riolita, andesita y cuarzo, siendo la riolita el componente más abundante. En algunos afloramientos aparece bien consolidado, pero en otros muy deleznable. Los cantos son de subangulares a redondeados. Presenta una matriz arenosa de grano fino que le da una tonalidad de café claro a rosado. Los afloramientos son masivos y forma lomeríos y bajos topográficos. En el área de Nuevo Cimatario esta roca tiene intercalados lentes de color blanco, que contiene pómez y cuarzo. A unos tres kilómetros al noreste de Aldama y al sur de El Caracol (Figura 2) se presenta con estratificación delgada, con clastos bien clasificados y de subangulares a redondeados. En un afloramiento pequeño que se encuentra al sur de El Guangoche se presenta como arenisca de grano grueso. En ese lugar la clasificamos como arenisca conglomerática, está mal consolidada, sus cantos son de riolita, ignimbrita, cuarzo y feldespato y sus tamaños llegan a alcanzar hasta $5 \mathrm{~cm}$. En este lugar se presenta con estratificación gradada normal.

El Conglomerado Santa Catarina yace bajo la Ignimbrita San Nicolás y hacia su parte baja contiene intercalada a la ignimbrita El Carrizo. El espesor del Conglomerado Santa Catarina se estimó como mínimo en $150 \mathrm{~m}$. Por ser anterior a la Ignimbrita San Nicolás su edad se ubica en el Oligoceno tardío.

\subsection{Ignimbrita San Nicolás (Osn)}

Sobre el Conglomerado Santa Catarina aparecen depósitos piroclásticos de composición ácida que fueron denominados Ignimbrita San Nicolás por Nieto-Samaniego (1992).

En el área de estudio esta unidad está formada de flujos piroclásticos, presenta colores morado, rosado, rojizo, café claro y raras veces blanco y grados distintos de soldamiento y desvitrificación. En las facies soldadas tiene estructuras de flama de colores blanco y gris, y fenocristales de sanidino contenidos en una matriz vítrea, también contiene cuarzo y algo de biotita. Al microscopio se aprecia que es una roca hipocristalina, se observan esquirlas de vidrio alineadas formando un flujo burdo alrededor de los fenocristales. Los fenocristales pueden llegar a medir hasta $1 \mathrm{~mm}$, de ellos aproximadamente el $60 \%$ son de sanidino y el resto son de cuarzo. Los feldespatos son ehudrales y subehudrales y los cuarzos subhedrales y anhedrales.

La unidad intemperiza en "lajas" y forma mesetas de poca inclinación. En el área de Nuevo Cimatario es de color café claro, con flamas blancas, está muy bien soldada, contiene fenocristales de cuarzo y poca biotita, contenidos en una matriz afanítica. En el camino que va a Mesas de Acosta ésta ignimbrita aparece de color rojizo, muy bien soldada, con abundantes fenocritales de sanidino y cuarzo que llegan a formar hasta un $40 \%$ de la roca, con matriz vítrea afanítica.

El espesor de estos depósitos dentro del área de estudio llega a ser hasta de $25 \mathrm{~m}$, aunque en muchos lugares aparece muy delgado, de solo unos cuantos metros. En su contacto inferior cubre al conglomerado Santa Catarina, aunque lo más común es encontrarla descansando directamente sobre la ignimbrita El Carrizo. En su contacto superior yace bajo las Gravas El Capulín, aunque en el área de El Nuevo Cimatario está directamente bajo el basalto Mesa San José y en la parte central del área cartografiada directamente bajo la Andesita La Ordeña.

La Ignimbrita San Nicolás fue fechada por NietoSamaniego et al. (1996) asignándole una edad de $24.8 \pm$ $0.6 \mathrm{Ma}$ (K-Ar en sanidino). En el presente trabajo se realizó un nuevo fechamiento en afloramientos alejados del lugar donde se reportó dicha edad, obteniéndose de $24.7 \pm 1.1$ 
Ma (K-Ar en sanidino) (Tabla 1), lo que confirma su edad de Oligoceno tardío.

\subsection{Gravas El Capulín (Mgc)}

Esta unidad fue propuesta por Martínez-Reyes (1987) para referirse a depósitos conglomeráticos continentales no consolidados y en varias localidades epiclásticos, que yacen bajo los basaltos de meseta de edad miocénica, que afloran en la Sierra de Guanajuato. Nieto-Samaniego (1992) cartografió esta unidad en una zona localizada inmediatamente al norte del área de estudio, y la describió como gravas y arenas no consolidadas, con estratificación poco desarrollada y en muchos casos sin estratificación, que yacen bajo el Basalto Mesa San José. Dentro del área cartografiada aparece en afloramientos muy alejados uno del otro, y en ella incluimos conglomerados y depósitos epiclásticos que yacen sobre la Ignimbrita San Nicolás y bajo la Andesita La Ordeña o el Basalto Mesa San José (Figura 2).

Se trata de una roca conglomerática de estratificación gradual burda con clastos de $1 \mathrm{~cm}$ y hasta $50 \mathrm{~cm}$, incluidos una matriz arenosa. Los clastos son principalmente de ignimbrita riolítica y de andesita, están mal clasificados y son de angulares a subangulares. En Agua Zarca el depósito se presenta como un flujo de detritos. En Las Fuentes tiene clastos muy mal clasificados y completamente angulares, contiene bloques de hasta un metro, no se le observa estratificación, está mal consolidado y presenta una matriz arenosa en la que se observó pómez, obsidiana y, ocasionalmente, trozos de carbón. En Rancho Nuevo se presenta como una brecha mal clasificada con clastos de angulosos a subangulosos de ignimbrita, riolita y andesita, siendo esta última la de mayor proporción, con el $40 \%$ aproximadamente. La matriz es arenosa de coloración blanquecina a rosada.

Las Gravas El Capulín sobreyacen discordantemente a la Ignimbrita San Nicolás e infrayacen a la Andesita La Ordeña. En Agua Zarca, cerro la Hacienda y meseta Rancho Nuevo está directamente abajo del Basalto Mesa San José. Por ocupar esa posición estratigráfica su edad queda ubicada en el Mioceno temprano.

\subsection{Arenisca Valencianita (Mtv)}

La arenisca Valencianita aflora en la parte noroeste del área de estudio. Hemos adoptado ese nombre ya que en el pueblo Valencianita aflora un paquete potente de estas rocas. Se trata de arenisca de grano fino de color blanco amarillento y café claro. La arenisca es fina, con estratificación laminar, presenta zonas con estratificación cruzada. Los componentes de la arenisca son cuarzo, feldespato y fragmentos líticos de ignimbrita y de riolita, el cementante es calcita, la cual es la que le da el color blanco característico a esta unidad. El rasgo más característico es la presencia de un horizonte de travertino de color blanco. El espesor de dicha capa oscila entre tres y cinco metros, y presenta en su interior las típicas formas contorsionadas de los depósitos travertinos. Inferimos que se trata de rocas sedimentarias continentales depositadas en un ambiente lacustre.

La arenisca Valencianita está depositada sobre la Ignimbrita San Nicolás, apreciándose una discordancia angular suave, y yace bajo el Basalto Mesa San José. Se le estima una potencia de $110 \mathrm{~m}$, medidos en la meseta que está al norte del poblado de Peñitas (Figura 2). Dada la posición estratigráfica que ocupa, puede considerarse contemporánea a las Gravas El Capulín y asignarle una edad de Mioceno temprano.

\subsection{Andesita La Ordeña (Mao)}

Esta unidad fue cartografiada originalmente en el área de estudio por Ramos-Salinas y Flores-Castro (1992) y posteriormente por Cerca-Martínez (1998), quien la describió como una unidad que aflora en amplias mesas compuestas por domos y derrames, asociados a volcanismo de tipo fisural y central.

La unidad se compone de derrames de andesita de coloración gris oscuro a verdoso que forman escarpes pronunciados. En afloramiento se observa como derrames masivos de lava. La mineralogía que se observó en muestra de mano es de plagioclasa y piroxeno inmersos en una matriz microcristalina. Intemperiza con colores café grisáceo y púrpura. En los alrededores del poblado La Ordeña hay domos de composición andesítica emplazados en los derrames de lava (Figura 2). Dichos domos también se incluyen en esta unidad.

La Andesita La Ordeña descansa sobre las Gravas El Capulín y yace bajo el Basalto Mesa San José. El espesor es muy variable y se estimó un máximo de $320 \mathrm{~m}$. Los derrames de esta unidad fueron fechados por Ramos-Salinas y Flores-Castro (1992) por el método K-Ar, obteniendo edades entre 12 y 14 Ma. Cerca-Martínez et al. (2000) también la fecharon por el método K-Ar en roca entera, obteniendo una edad de $14.3 \pm 0.5$ Ma. Estas edades la ubican en el Mioceno medio.

\subsection{Basalto Mesa San José (Mms)}

Nieto-Samaniego (1992) dio este nombre a una unidad que se encuentra en la parte superior de la Mesa San José, ubicada $4 \mathrm{~km}$ al nororiente del área de estudio. Esta unidad es de color gris oscuro e intemperiza a color rojo y amarillo ocre. Está formada de derrames de lavas sobrepuestos, de composición basáltico-andesítica. Los derrames aparecen horizontales, masivos y de espesor uniforme. En muestra de mano muchos derrames presentan cristales de olivino y piroxeno, en algunos otros está presente hornblenda. La textura es comúnmente afanítica, de apariencia vítrea. El basalto Mesa San José forma mesetas que en algunos lugares llegan a medir sólo $10 \mathrm{~m}$. En el área de Rancho Nuevo la unidad es de color negro e intemperiza a gris claro, con 
matriz afanítica vítrea y porfídica, con fenocristales de plagioclasa.

En las cercanías de Mandujano se encontró una dacita de hornblenda color rojo claro intercalada en el basalto. Tanto en la meseta ubicada un kilómetro al poniente de Rancho Nuevo, como en la de Rinconcillo, aparece un depósito piroclástico de composición dacítica encima del basalto, tanto la dacita como el depósito piroclástico fueron cartografiados como parte del Basalto Mesa San José.

El espesor fue estimado por Nieto-Samaniego (1992) en $40 \mathrm{~m}$ en la Mesa San José. Su edad ha sido reportada por varios autores, en la región de San Miguel de Allende, Gto., Carranza-Castañeda et al. (1994) obtuvieron edades de 12.5 \pm 0.9 y $10.7 \pm 0.7 \mathrm{Ma}$ (K-Ar roca entera) y Pérez-Venzor et al. (1996) de $11.1 \pm 0.4 \mathrm{Ma}$ (K-Ar roca entera); dentro del área de estudio Hasenaka (1994) obtuvo una edad de $10.2 \pm$ 0.2 Ma por el método (K-Ar, roca entera) y Cerca-Martínez et al. (2000) edades de $12.4 \pm 0.3$ y $10.6 \pm 0.3 \mathrm{Ma}$ en roca entera y entre $14.6 \pm 0.3$ y $12.2 \pm 0.2 \mathrm{Ma}$ en plagioclasa.

\subsection{Rocas volcánicas de la Faja Volcánica}

Transmexicana (MQv)

Esta unidad está formada por dos miembros. El miembro inferior consiste de conos cineríticos que afloran en la parte sur del área estudiada (Figura 2). La litología de los conos está formada en su totalidad por cenizas con granulometrías menores a $2 \mathrm{~mm}$, pero también contiene fragmentos líticos de basalto color negro y vesicular que pueden llegar a medir hasta $60 \mathrm{~cm}$. El color que presenta la toba es amarillo oscuro. Tiene estratificación delgada, con basculamientos de $15^{\circ}$. Las edades que se les asigna a los conos van del Plioceno al Cuaternario (Hasenaka y Carmichael, 1985). Los volcanes de esta unidad pueden correlacionarse con el campo volcánico Michoacán-Guanajuato, donde se ha reportado la presencia de 901 conos cineríticos distribuidos en $40000 \mathrm{~km}^{2}$ (Hasenaka y Carmichael, 1987).

El miembro superior también aflora en la parte sur del área (Figura 2). Se forma de volcanes monogenéticos con derrames de basalto vesicular, con fenocristales de plagioclasa de hasta $1 \mathrm{~cm}$. Los conos son de escoria, no se les aprecia cráter. En la falda y parte media de los volcanes se pueden encontrar bombas, algunas de las cuales llegan a medir hasta $1 \mathrm{~m}$ de largo. Cada volcán tiene derrames de basalto, vesiculares y muy oscuros que forman mesetas con escarpes poco pronunciados. Las inclinaciones que presentan los basaltos y los depósitos piroclásticos se interpretaron como primarias, producto de la topografía preexistente o la del mismo volcán. Los derrames a veces presentan tanto estructura de tipo aa como pahoehoe. Los volcanes están alineados aproximadamente siguiendo el rumbo de la falla El Bajío. La edad de esta unidad también es Plioceno-Cuaternario (Hasenaka y Carmichael, 1985).

\section{Estructuras principales}

El conjunto de fallas más importantes que se reconoció en el área de estudio está formado por estructuras localizadas sobre el sistema de fallas El Bajío, el cual está representado, en esa zona, por fallas con dos direcciones preferentes, una NO y la otra NE-ENE (Figura 2). Adicionalmente se cartografiaron, en cantidad menor, fallas con rumbo Norte-Sur, las cuales no forman sistemas importantes. Se lograron medir en total 61 fallas, de las cuales 36 mostraron estrías e indicadores cinemáticos que permitieron conocer su cinemática (Figura 3A). Aunque en las fallas que no mostraban estrías es difícil determinar la dirección y sentido de movimiento, al considerar los desplazamientos aparentes de las unidades estratigráficas sí fue posible inferir que tienen desplazamiento preponderantemente normal con componentes laterales.

Las fallas medidas en el campo presentan una dispersión importante en sus rumbos (Figura 3A). En aquellas fallas en las que se midieron estrías e indicadores cinemáticos se dedujeron desplazamientos preponderantemente normales con componentes menores de desplazamiento lateral (Figura 3B). Se obtuvieron tensores de paleoesfuerzos por los métodos de ángulos diedros (Angelier y Mechler, 1977) y del análisis dinámico propuesto por Spang (1972) (Figuras 3B, C).

\subsection{Fallas NO}

El elemento estructural más prominente es el conjunto de estructuras que forma la falla El Bajío. Dentro del área de estudio dicha falla forma un rasgo morfológico de aproximadamente $20 \mathrm{~km}$ y forma el límite meridional de la $\mathrm{MC}$, separándola de una planicie de relleno aluvial conocida como El Bajío. El escarpe de la falla El Bajío muestra un grado de erosión avanzado, presentando desniveles topográficos máximos de $250 \mathrm{~m}$. No fue posible estimar su desplazamiento real pues las unidades desplazadas están sepultadas por el relleno sedimentario en el bloque hundido (Figura 2). Varias de las estructuras que conforman a la falla El Bajío cortan derrames del basalto Mesa San José, de $c a$. $12 \mathrm{Ma}$, por lo que consideramos que los desplazamientos más recientes de la falla ocurrieron en el Mioceno tardío. Las fallas NO tuvieron desplazamientos más antiguos, los cuales fueron documentados durante la cartografía geológica, donde las fallas de dirección NO están cubiertas por las ignimbritas El Carrizo y/o San Nicolás (Figura 2). En la parte norte-centro del área, cerca de Mesas de Almanza, se cartografiaron fallas de rumbo NO que sí afectan a la ignimbrita El Salto y a la ignimbrita El Carrizo, pero no a la Ignimbrita San Nicolás.

\subsection{Fallas NE-ENE}

Este sistema aparece en la parte noroeste del mapa de la Figura 2. Allí aparecen fallas con rumbos que van de NE a 


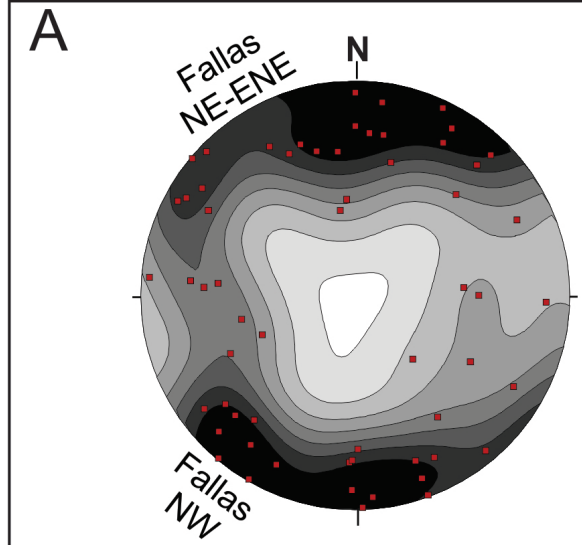

Total de fallas medidas en el área de estudio, $\mathrm{N}=61$, polos en proyección equiareal, hemisferio inferior.

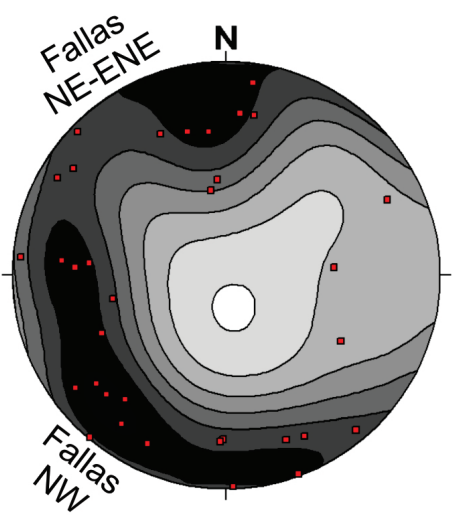

Fallas en las que se midieron estrías, $\mathrm{N}=36$, polos en proyección equiareal, hemisferio inferior.

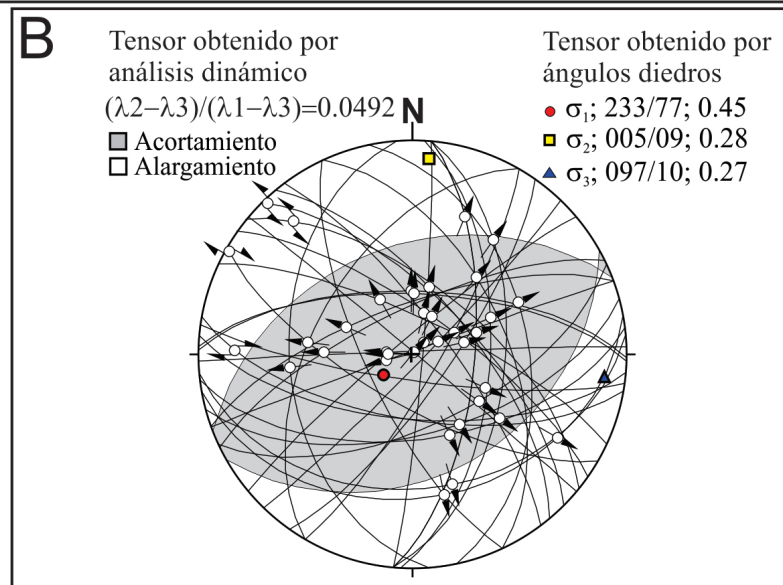

Todas las fallas con estrías, N=36, Proyección ciclográfica, estría y sentido de desplazamiento del bloque del alto en proyección equiareal, hemisferio inferior.

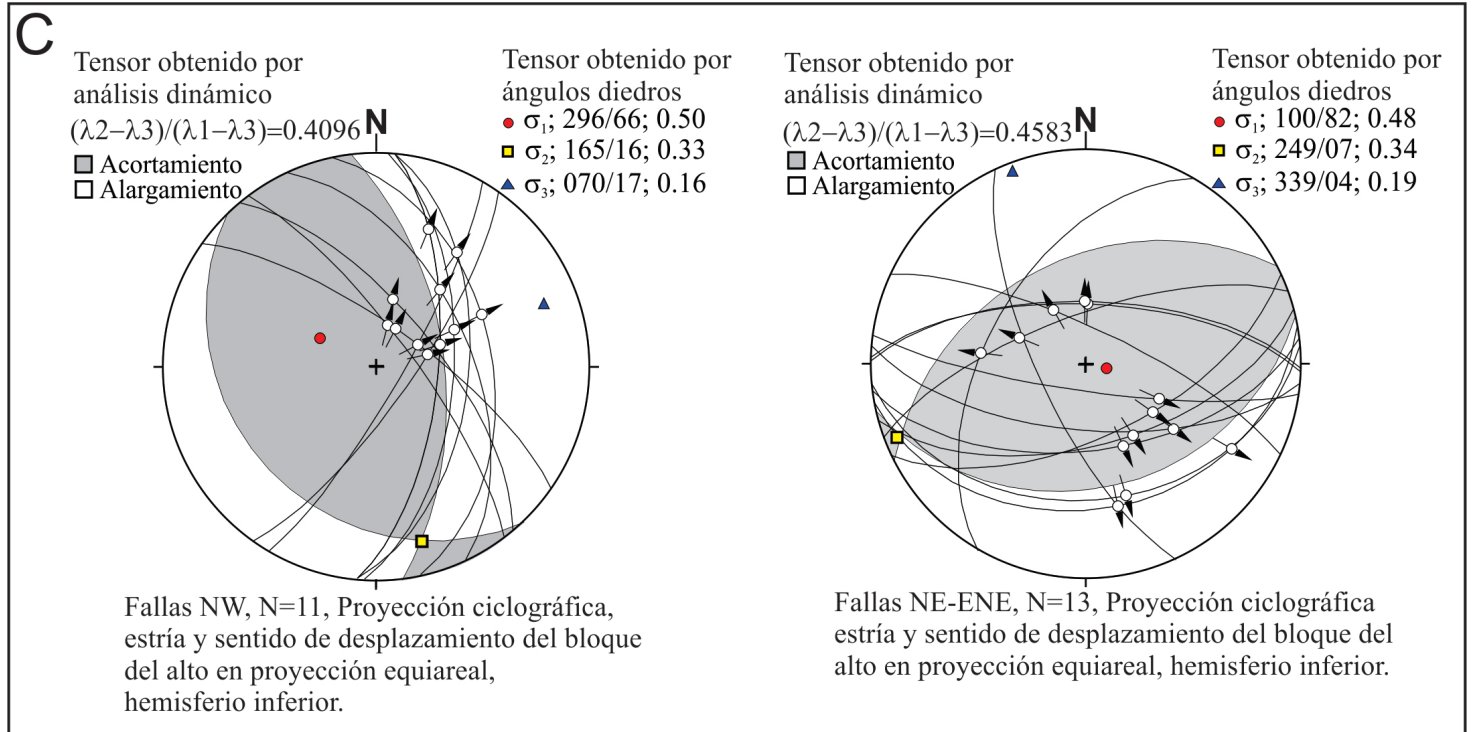

Figura 3. Representación gráfica de los datos estructurales. Se utilizó el software comercial Tectonics FP (v. 1.701.1164 (C) Franz Reiter y Peter Acs) para los cálculos realizados. Se usó el método de análisis dinámico propuesto por Spang (1972) para obtener los tensores que se presenta a manera de la "pelota de playa" y las razones de deformación mostradas en la parte superior izquierda de B y C. Los eigenvectores mostrados en la parte superior derecha de B y C se calcularon por el método de ángulos diedros (Angelier y Mechler, 1977). El número de fallas en C es distinto al de B debido a que se eliminaron las fallas verticales y aquellas descartadas por el programa al realizar el ajuste al paleotensor obtenido. 
ENE, que desplazan a las ignimbritas oligocénicas, siendo la Ignimbrita San Nicolás la unidad más reciente que está afectada por esas estructuras. Las fallas tienen echados tanto al SE como al NO y desplazamientos verticales menores a $50 \mathrm{~m}$, ponen en contacto a la Ignimbrita San Nicolás con el Conglomerado Santa Catarina y con la formación Peñitas.

Los desplazamientos observados son de tipo normal con componentes laterales menores, principalmente izquierdas. En la esquina nororiental del área de estudio las fallas cortan al Basalto Mesa San José, por lo que se infiere que los movimientos más recientes son del Mioceno tardío o posteriores. En varios lugares se documentó que fallas NE a ENE desplazan a fallas de dirección NO, por ejemplo en las faldas de la meseta de Rancho Nuevo. Esta relación había sido reportada en la región por Nieto-Samaniego (1992), quien infirió que las fallas NE-ENE fueron las últimas en mostrar actividad, y que tanto fallas NO como NE-ENE tuvieron varias etapas de actividad previa. Ambas inferencias son consistentes con nuestras observaciones en el área de estudio. Las fallas medidas en el campo presentan dispersión tanto en rumbo como en la dirección de sus estrías (Figura 3C). De la misma manera que en el caso de las fallas Noroeste, se hizo un ejercicio de inversión de datos con las fallas medidas que presentan rumbos al NEENE (Figura 3C).

\subsection{Fallas N-S}

Se cartografiaron algunas fallas de rumbo N-S que tienen desplazamientos pequeños, menores a $20 \mathrm{~m}$. Los rumbos varían de $\mathrm{N} 3^{\circ} \mathrm{E}$ a $5^{\circ} \mathrm{E}$, con echados tanto al $\mathrm{E}$ como al O (Figura 3A). Presentan desplazamientos de tipo normal, sin componentes laterales significativas. Las fallas más grandes con esta dirección fueron cartografiadas en la parte sur del área de estudio, donde se observa que afectan a rocas volcánicas de la FVTM, por esa razón se le asigna una edad de actividad entre el Plioceno y el Cuaternario.

\subsection{Calderas y cráteres}

En el área de estudio existen una caldera y un cráter. La más importante por su tamaño es la caldera excéntrica La Ordeña, definida por Ramos-Salinas y Flores-Castro (1992). La caldera La Ordeña se localiza a cinco kilómetros al norte de Salamanca, Guanajuato, en el límite de la parte centro septentrional de la FVTM y la porción meridional de la MC (Ramos-Salinas y Flores-Castro, 1992). Esa depresión vulcano-tectónica presenta forma elíptica de $12 \mathrm{~km}$ de longitud, en su eje mayor, truncada en su extremo sudoccidental por fallas normales escalonadas de orientación NO (falla El Bajío), buzante hacia el SO y por una estructura rectilínea de orientación ENE que limita el borde noroccidental. El volcanismo asociado a la caldera La Ordeña es de tipo central y fisural, con emisiones predominantemente andesítico-basálticas de edad Mioceno-Plioceno, correspondientes a la Andesita
La Ordeña ya descrita. En la parte NE de la caldera hay varios domos andesíticos emplazados en los bordes de la estructura elíptica.

El cráter aquí denominado cráter Temascatío se encuentra a $17 \mathrm{~km}$ al norte de la ciudad de Salamanca en la porción noroccidental de la carta. Es de forma circular y tiene un diámetro aproximado de $1.5 \mathrm{~km}$. Los bordes son verticales con desniveles de aproximadamente tres metros y están formados en la Ignimbrita San Nicolás, que se presenta fracturada y brechada. Alrededor del escarpe aflora un anillo de ceniza y escoria basáltica que se puede observar de decenas a cientos de metros a la redonda, y rellenando el cráter hay derrames de lava basáltica que no alcanzaron a desbordarlo.

\section{Discusión}

Las unidades volcánicas identificadas en el área de estudio se pueden correlacionar con las descritas por Cerca-Martínez et al. (2000) en la parte sur de la Sierra de Guanajuato, así como con los grupos volcánicos propuestos por Nieto-Samaniego et al. (1996) para la Mesa Central de México (Figura 4). El control cronoestratigráfico en la parte sur de la sierra de Guanajuato es bastante bueno, ya que se cuenta con fechamientos isotópicos de gran parte de la columna estratigráfica. Sin embargo, la mayoría de dichos fechamientos son K-Ar, lo que no permite una separación fina de los eventos volcánicos, dados los errores en las edades reportadas. No obstante lo anterior, sí es posible diferenciar conjuntos volcánicos que pueden ser distinguibles tanto espacial como temporalmente.

En este trabajo se identificaron cuatro conjuntos de rocas volcánicas (Figura 4): (1) el volcanismo del Distrito Minero de Guanajuato, de edad Oligoceno temprano, cuya unidad cimera (Riolita Chichíndaro) es representativa de un magmatismo efusivo de domos y derrames riolíticos que aflora en la Mesa Central (Nieto-Samaniego et al., 1996). (2) Un grupo ignimbrítico ampliamente distribuido en la Mesa Central, con alcance estratigráfico Oligoceno tardío a la base del Mioceno y que yace sobre el conjunto de domos riolíticos. Dichas rocas piroclásticas aparecen en conjuntos de unidades volcánicas, mayormente ignimbritas, depósitos de caída y epiclásticos, que configuran zonas o campos volcánicos que se circunscriben a regiones y/o lapsos particulares. Dentro del área de estudio, uno de esos conjuntos está formado por las unidades ignimbrita El Salto, formación Rancho Nuevo, Andesita Presa de Manantiales, ignimbritas El Carrizo y San Nicolás, junto con las ignimbritas superior y media de Cerca-Martínez et al. (2000). Aunque la fuente de emisión de esas unidades no se conoce, el conjunto volcánico puede distinguirse del volcanismo del Distrito Minero de Guanajuato dada su edad y ubicación geográfica (Figuras 2, 4). (3) La unidad denominada "andesita y basalto del Mioceno medio-tardío", cuyas rocas han sido reportadas en gran parte de la Mesa 


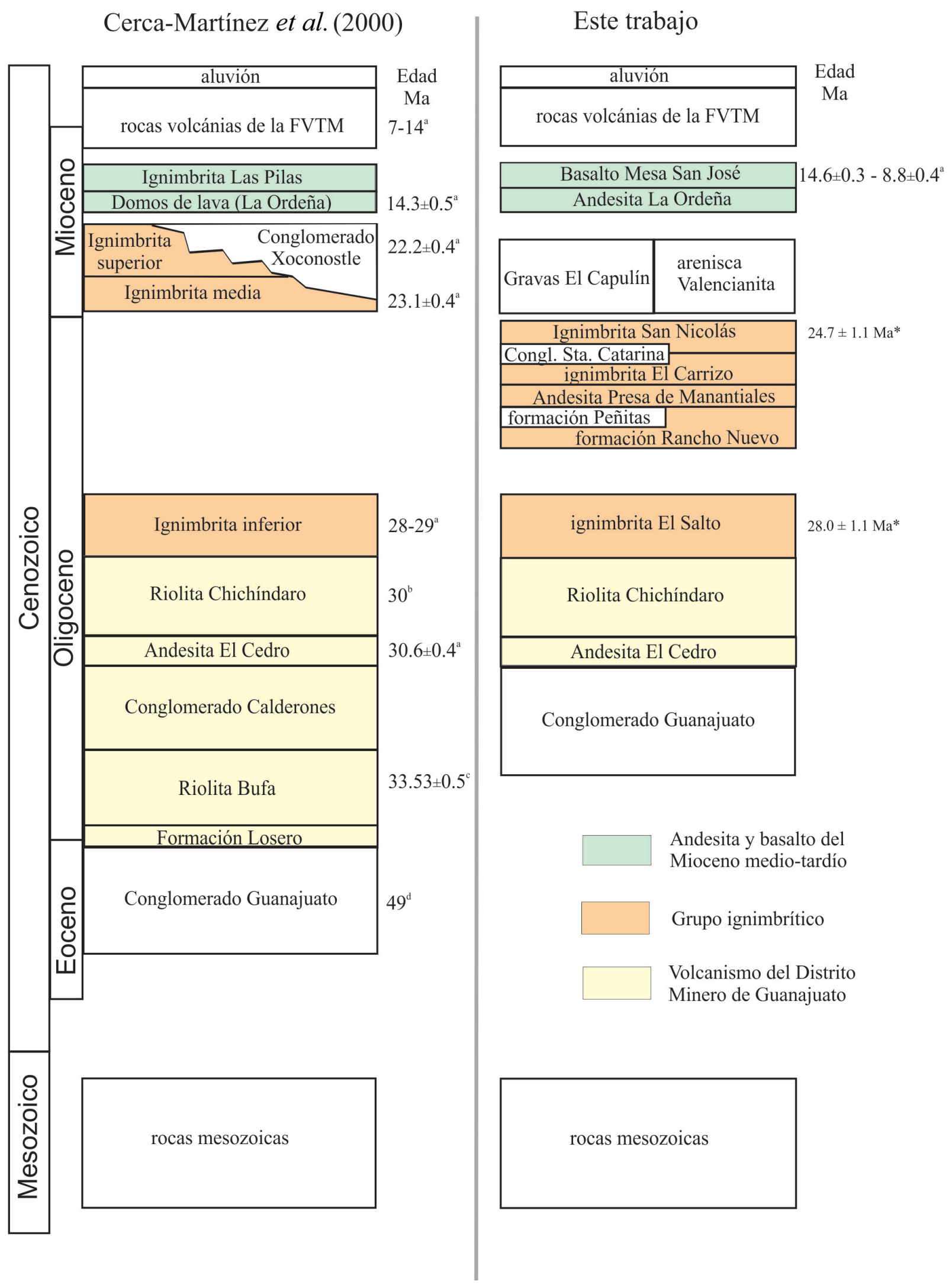

Figura 4. Correlación estratigráfica entre las unidades cartografiadas en el área de estudio y las unidades reconocidas y compiladas en la región por Cerca-Martínez et al. (2000). * Edades obtenidas por Nieto-Samaniego et al. (2005), los datos isotópicos se reportan en la Tabla 1, a edades reportadas por Cerca-Martínez et al. (2000), ${ }^{\mathrm{b}}$ promedio de edades K-Ar en sanidino obtenidas por Nieto-Samaniego et al. (1996), ${ }^{\mathrm{c}}$ edad Ar-Ar en sanidino obtenida por Báez-López (Comunicación personal extraída de su tesis de maestría en proceso: "Estratigrafía de la parte sur del Distrito Minero de Guanajuato":

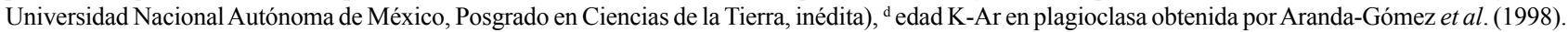


Central por Nieto-Samaniego et al. (1996) y que en el área de estudio está representada principalmente por los productos volcánicos de la "caldera La Ordeña". (4) Por último, se separaron las rocas pertenecientes al volcanismo de la Faja Volcánica Transmexicana, cuya edad va del Plioceno al Pleistoceno dentro del área.

De los conjuntos volcánicos descritos, consideramos que las rocas ácidas efusivas y la cubierta ignimbrítica forman parte del volcanismo de la Sierra Madre Occidental, esto dada su composición y edad. De la misma manera, resulta fácil correlacionar las rocas de edad Plioceno-Cuaternario con el magmatismo formador de la Faja Volcánica Transmexicana. Adicionalmente, nuestra cartografía muestra que hay un evento volcánico "transicional" entre ambos conjuntos de rocas, formado por rocas de composición andesítica y basáltica (Andesita La Ordeña y Basalto Mesa San José). Dicho magmatismo representa una fase temprana del magmatismo de la Faja Volcánica Transmexicana y ha sido reportada en la literatura con anterioridad (e.g., Cerca-Martínez et al., 2000)

El análisis de los datos de falla se hizo tanto para el conjunto total de fallas como separando los sistemas N-S y NO-SE de los E-O y NE-ENE (Figura 3). La superposición de eventos de fallamiento durante el Cenozoico en la MC ha sido documentada profusamente (e.g., Nieto-Samaniego et al., 1997, 1999c, Tristán-González et al., 2009), lo que también se pudo determinar en el área cartografiada. Una opción para explicar que haya al menos dos conjuntos de fallas con distinto rumbo que presentan relaciones de corte no unívocas, es que cada sistema de fallas se haya formado en etapas distintas y que hayan experimentado varias reactivaciones obedeciendo estados distintos y alternantes de deformación (o de esfuerzo), o bien, una segunda opción es que en su origen, o posteriormente a su formación, hayan tenido actividad bajo un solo sistema de deformación tridimensional. Si se realiza la inversión de todos los datos se obtiene una dirección de extensión cercana a E-O (Figura 3B) lo cual no parece tener mucho sentido para el conjunto de fallas normales de rumbos NO y NE a ENE que fueron cartografiadas. Sin embargo, considerando separadamente los datos para cada dirección preferente de fallas, se obtiene una dirección de extensión horizontal máxima $\mathrm{N} 70^{\circ} \mathrm{E}$ para las fallas N-S y NO y una dirección $\mathrm{N} 21^{\circ} \mathrm{O}$ para las fallas NE a ENE (Figura 3C). Dichas direcciones de esfuerzos principales corresponden también a las orientaciones de los eigenvectores de deformación finita asociadas a cada conjunto de fallas (Spang, 1972; Angelier y Mechler, 1977). Hay evidencia de que las fallas con rumbos $\mathrm{E}$ a NE tuvieron actividad oligocénica en la sierra de Guanajuato cortando la ignimbrita Cuatralaba de $30 \mathrm{Ma}$ (Botero-Santa, 2011), estas fallas difícilmente se hubieran podido reactivar bajo un sistema de esfuerzos con el esfuerzo compresivo mínimo orientado al ENE y junto con las fallas NO, ya que la orientación más desfavorable para la reactivación de una estructura es que su rumbo sea paralelo a la dirección de extensión máxima (e.g., Alaniz-
Álvarez y Nieto-Samaniego, 1997). Para la explicación que los dos sistemas se reactivaron sincrónicamente es necesario que la razón de esfuerzos fuera cercana a cero, es decir el esfuerzo principal intermedio y el esfuerzo principal mínimo debieran haber sido iguales y las fallas aparecerían con componente normal en todas direcciones. Los resultados de campo y de inversión de estrías no muestran esto por lo que, en el área de estudio, la explicación más viable es que se hayan alternado los sistemas de fallas NO-SE y el E-NE, apoyando la primera hipótesis propuesta.

De las relaciones de corte entre unidades de roca y fallas que fueron documentadas durante la cartografía, podemos asegurar que el emplazamiento de las unidades volcánicas ocurrió durante un lapso en el que tuvo lugar fallamiento de tipo preponderantemente normal. La estructura volcánica principal es la Caldera La Ordeña, cuyos productos son de composición mayormente andesítica. Se ubica sobre la traza de la falla El Bajío y es cortada por fallas más jóvenes de rumbos NO y NE. Lo anterior sugiere que su actividad fue contemporánea con fallamiento y que las estructuras influyeron en la localización de la caldera. Por otra parte, la cubierta de ingimbritas de composición riolítica se extiende fuera del área de estudio, lo que indica que el volumen de esas rocas es considerable. Sin embargo, no se han identificado estructuras caldéricas a las que se puedan asociar las ignimbritas, abriendo la posibilidad de que su emplazamiento haya sido fisural. La presencia de diques piroclásticos observados en el campo apoya esta idea, pero no se realizó un levantamiento adecuado para probar esa hipótesis.

\section{Conclusiones}

A partir de la cartografía realizada en la zona de Salamanca se identificaron dieciséis unidades litoestratratigráficas, cinco de ellas nuevas (formación Rancho Nuevo, formación Peñitas, ignimbrita El Salto, ignimbrita El Carrizo y arenisca Valencianita). Las formaciones Peñitas y arenisca Valencianita son depósitos lacustres, por lo que evidencian un paleolago extenso que estuvo localizado en la parte noroeste del área cartografiada, dicho lago podría tener especial interés en la región, dados los depósitos de travertino que contiene.

En este trabajo se identificaron tres conjuntos de rocas volcánicas: (1) el volcanismo del Distrito Minero de Guanajuato con alcance estratigráfico Oligoceno temprano, dicho conjunto volcánico se circunscribe al Distrito Minero de Guanajuato y solamente se extienden fuera de él y de manera regional las unidades

Riolita Chichíndaro y Andesita El Cedro; (2) el grupo ignimbrítico de la Mesa Central con alcance estratigráfico Oligoceno tardío a la base del Mioceno, el cuál ha sido identificado en gran parte de la Mesa Central y (3) la unidad de "andesita y basalto del Mioceno medio-tardío", cuyas rocas han sido reportadas en gran parte de la Mesa 
Central por Nieto-Samaniego et al. (1996) y que en el área de estudio está representada principalmente por los productos volcánicos de la "caldera La Ordeña". Entre estos conjuntos volcánicos aparecen sedimentos continentales que representan etapas de depósito en fosas tectónicas, ocurrida durante los lapsos de baja o nula actividad volcánica.

Se identificaron dos grupos de fallas como los más importantes. En ambos casos el acortamiento principal ocurrió en dirección sub-vertical, reflejando que ambos sistemas están formados por fallas de tipo normal. Para el sistema NO se calculó una dirección principal de alargamiento horizontal de $\mathrm{N} 70^{\circ} \mathrm{E}$ y para las fallas NE-ENE una dirección $\mathrm{N} 21^{\circ} \mathrm{O}$.

\section{Agradecimientos}

Esta investigación fue financiada por los proyectos CONACyT 80142 y 049049, así como por el Centro de Geociencias de la UNAM. Se agradece al Ing. Isidro Loza Aguirre por su ayuda en la elaboración de la Figura 2, así como por sus comentarios sobre la geología del centro de México. También expresamos nuestro agradecimiento al Sr. Juan Tomás Vázquez Ramírez por su asistencia en la elaboración de láminas delgadas y separación de minerales para fechamientos isotópicos. Las revisiones por parte del Dr. Margarito Tristán González y el Dr. Gabriel Valdez Moreno ayudaron a mejorar sustancialmente este trabajo.

\section{Referencias}

Alaniz-Álvarez, S.A., Nieto-Samaniego, A.F., 1997, Representación gráfica de los dominios de ruptura y deslizamiento: aplicación a la falla de Oaxaca, México: Revista Mexicana de Ciencias Geológicas, 14, 26-37.

Alvarado-Méndez, H., López-Ojeda, J.A., Caballero-Martínez, J.A., 1998, Carta Geológica-Minera Guanajuato, F14-C43, Guanajuato, escala 1:50000: Aguascalientes, Aguascalientes, México, Servicio Geológico Mexicano, Secretaría de Economía, un mapa, dos secciones y texto explicativo.

Angelier, J., Mechler, P., 1977, Sur une méthode graphique de recherché des contraintes principales également utilisable en tectonique et en séismologie: la méthode des dièdres droits: Bulletin de la Société Géologique de France, 7, 1309-1318.

Aranda-Gómez, J. J., Aranda-Gómez, J. M. y Nieto-Samaniego, A. F., 1989, Consideraciones acerca de la evolución tectónica durante el cenozoico de la Sierra de Guanajuato y la porción meridional de la Meseta Central: Universidad Nacional Autónoma de México, Instituto de Geología, Revista, 8, 33- 46.

Aranda-Gómez, J. J., McDowell, F., 1998, Paleogene extension in the southern Basin and Range province of Mexico: syndepositional tilting of Eocene red beds and Oligocene volcanic rocks in the Guanajuato Mining District: International Geology Review, 40, 116-134.

Bostford, C. W., 1909, Geology of Guanajuato District, Mexico: The Engineering and Mining Journal, 87, 691-694.

Botero-Santa, P., 2011, Origen y evolución de la falla de El Bajío en su sector noroeste: Querétaro, Qro., México, Centro de Geociencias de la Tierra, Universidad Nacional Autónoma de México, tesis de maestría, $113 \mathrm{p}$.
Carranza-Castañeda, O., Petersen, M.S., Miller, W. E., 1994, Preliminary investigation of the Geology of northern San Miguel de Allende area, northeastern Guanajuato, Mexico: Geology Studies, 40, 1-9.

Cerca-Martínez, L.M., 1998, Relación estratigráfica y geocronológica entre el volcanismo de la Sierra Madre Occidental y el Cinturón Volcánico Mexicano en la parte sur de la Sierra de Guanajuato. Implicaciones geocronológicas y tectónicas: Ensenada, B.C., México, Centro de Investigación Científica y de Educación Superior de Ensenada, tesis de maestría, $105 \mathrm{p}$.

Cerca-Martínez, L. M., Aguirre-Díaz, G. J., López-Martínez, M., 2000, The geologic evolution of the southern Sierra de Guanajuato, Mexico: a documented example of the transition from the Sierra Madre Occidental to the Mexican Volcanic Belt: International Geology Review, 42, 131-151.

Echegoyén-Sánchez, J., Romero-Martínez S., Velázquez-Silva, S., 1970, Geología y yacimientos minerales de la parte central del Distrito Minero de Guanajuato: Consejo de Recursos Naturales No Renovables, Boletín, 75, 48 p.

Ferrari, L., Conticelli, S., Vaggelli, C., Petrone, C., Manetti, P., 2000, Late Miocene mafic volcanism and intra-arc tectonics during the early development of the Trans-Mexican Volcanic Belt: Tectonophysics, $318,161-185$.

Gómez-Tuena, A., Orozco-Esquivel, M.T., Ferrari, L., 2005, Petrogénesis ígnea de la Faja Volcánica Transmexicana: Boletín de la Sociedad Geológica Mexicana, 57, 227-283.

Gross, W.H., 1975, New ore discovery and source of silver-gold veins, Guanajuato, Mexico: Economic Geology, 70, 1175-1189.

Hasenaka, T., 1994, Size, distribution, and magma output rate for shield volcanoes of the Michoacán-Guanajuato Volcanic Field, Central Mexico: Journal of Volcanology and Geothermal Research, 63, 13-31.

Hasenaka, T., y Carmichael, I.S.E., 1985, The cinder cones of MichoacánGuanajuato, central Mexico-their age, volume, and distribution, and magma discharge rate: Journal of Volcanology and Geothermal Research, 25, 105-124.

Hasenaka, T., Carmichael, I.S.E., 1987, The cinder cones of MichoacánGuanajuato, central Mexico-petrology and chemistry: Journal of Petrology, 28, 241-269.

Labarthe-Hernández, G., Tristán-González, M., Aranda-Gómez, J. J., 1982, Revisión estratigráfica del Cenozoico de la parte central del estado de San Luis Potosí: San Luis Potosí, S.L.P, México, Instituto de Geología, Universidad Autónoma de San Luis Potosí, Folleto Técnico, 85, 208 p., 1 mapa, 2 secciones.

López-Ojeda, J.A., Loaeza-García, J. P., Zárate-Barradas, R., 2002, Carta geológico-minera Aldama, F14-C53, Aldama, escala 1:50000: Aguascalientes, Ags., México, Servicio Geológico Mexicano, Secretaría de Economía, un mapa y texto explicativo.

Martínez-Reyes, J., 1987, Excursión a la Sierra de Guanajuato, en Simposio sobre la geología de la región de la Sierra de Guanajuato, programa, resúmenes y guía de excursión: Guanajuato, Gto., México, Estación Regional del Centro, Instituto de Geología, Universidad Nacional Autónoma de México, 50-70.

Martínez-Reyes, J., 1992, Mapa geológico de la Sierra de Guanajuato, con resumen de la geología de la Sierra de Guanajuato: Universidad Nacional Autónoma de México. Instituto de Geología, Cartas geológicas y mineras 8 , mapa de escala 1:100000 con texto explicativo en el reverso.

Nieto-Samaniego, A.F., 1990 (1992), Fallamiento y estratigrafía cenozoicos en la porción sudoriental de la Sierra de Guanajuato: Instituto de Geología, Universidad Nacional Autónoma de México, Revista, 9, 146-155.

Nieto-Samaniego, A.F., Macías-Romo, M.C., y Alaniz-Alvarez, S.A., 1996, Nuevas edades isotópicas de la cubierta volcánica cenozoica de la parte meridional de la Mesa Central, México: Revista Mexicana de Ciencias Geológicas, 13, 117-122.

Nieto-Samaniego, A.F., Alaniz-Alvarez, S.A. y Labarthe-Hernández, G., 1997, La deformación cenozoica poslaramídica en la parte meridional de la Mesa Central, México: Revista Mexicana de Ciencias Geológicas, 14, 13-25. 
Nieto-Samaniego, A.F., Alaniz-Alvarez, S.A., y Cerca-Martínez, M., 1999a, Carta Geológico-Minera San Miguel de Allende, F14C54, San Miguel de Allende, escala 1:50000: Aguascalientes, Ags., México, Consejo de Recursos Minerales, un mapa, secciones y texto explicativo.

Nieto-Samaniego, A.F., Alaniz-Alvarez, S.A., y Cerca-Martínez, M., 1999b, Carta Geológico-Minera Celaya, F14C64, escala 1:50000: Aguascalientes, Ags., México, Consejo de Recursos Minerales, un mapa, dos secciones y texto explicativo.

Nieto-Samaniego, A. F., Ferrari, L., Alaniz-Alvarez, S. A., LabartheHernández, G., y Rosas-Elguera, J., 1999c, Variation of Cenozoic extension and volcanism across the southern Sierra Madre Occidental Volcanic Province, Mexico: Geological Society of America Bulletin., 111, 347-363.

Nieto-Samaniego, A. F., Alaniz-Alvarez, S. A., Camprubí-Cano, A., 2005, La Mesa Central de México: estratigrafía, estructura y evolución tectónica cenozoica: Boletín de la Sociedad Geológica Mexicana, Tomo 52, 285-317.

Pérez-Flores, E., Mauvois-Guitteaud, R., Menguelle-López, J., MorenoVázquez, J. L., Soto-Araiza, R. G., López-Ojeda, J. A., 1999, Carta geológico-minera Querétaro, F14-10, Querétaro, escala 1:250000: Aguascalientes, Ags., México, Servicio Geológico Mexicano, Secretaría de Economía, un mapa, secciones y texto explicativo.
Pérez-Venzor, J. A., Aranda-Gómez, J. J., McDowell, F., Solorio-Munguía, J. G., 1996, Geología del volcán Palo Huérfano, Guanajuato, México: Revista Mexicana de Ciencias Geológicas, 13, 174-183.

Ramos-Salinas, A., Flores-Castro, S. 1992, La caldera excéntrica de La Ordeña, Salamanca, Estado de Guanajuato, en Convención sobre la evolución geológica de México y Primer Congreso de Mineralogía: Guanajuato, Gto., México, Universidad de Guanajuato, UNAM, 252-257.

Spang, J. H., 1972, Numerical Method for Dynamic Analysis of Calcite Twin Lamellae: Geological Society of America Bulletin, 83, 467472.

Tristán-González, M., Aguirre-Díaz, G. J., Labarthe-Hernández, G., TorresHernández, J. R., Bellon, H., 2009, Post-Laramide and pre-Basin and Range deformation and implications for Paleogene (55-25 Ma) volcanism in central Mexico: A geological basis for a volcanotectonic stress model: Tectonophysics, 471, 136-152.

Manuscrito recibido: Marzo 13, 2012.

Manuscrito corregido recibido: Junio 10, 2012.

Manuscrito aceptado: Julio 22, 2012. 